\title{
An acute and severe immunodeficiency syndrome due to a pancreatic ACTH-producing tumor
}

\author{
Monica Cevenini, Elena Guidetti, Giulia Cacciari, Eugenio Ruggeri, Davide Campana, \\ Paola Tomassetti, Roberto Corinaldesi
}

Dipartimento di Medicina Clinica. Università degli Studi di Bologna, Policlinico S. Orsola Malpighi, Bologna, Italia

Key words: Ectopic adrenocorticotropic hormone syndrome; Cushing's syndrome; NETs; Pancreatic neuroendocrine tumours

\begin{abstract}
We report a case of a 48 years old woman, with a rapidly progressing ACTH neuroendocrine tumor of the pancreas(PNET) and multiple liver metastases. The patient had previously suffered from peptic ulcer responsive to PPI inhibitors and hypertension poorly controlled by therapy. Admitted to the hospital for severe asthenia and abdominal pain, she was diagnosed poorly differentiated PNET with liver metastases, which were positive for synaptophysin, cytokeratin 7 and 9 , neuron specific enolase (NSE). Octreoscan scintigraphy was positive for somatostatin receptor in the pancreatic and in two liver lesions. A rapidly progressive Cushing syndrome developed, presenting with the classical physical symptoms, hypokal emia and Lysteria Monocytogenes meningitis. An ectopic ACTH production was confirmed and eventually the patient died of a septic shock within two months. The case reported focuses on the malignity and the rapid progression of a PNET producing ACTH and alerts on the possible fatal progression of these cases.
\end{abstract}

\section{Introduction}

Ectopic ACTH secreting tumors account for 20\% of Cushing's syndrome in Western countries and they are characterized by acute onset of hypercortisolism, signs of mineralocorticoid excess, weight loss, hyperpigmentation and immunodepression; they usually present with rapid progression of the disease (1-8).

About $50 \%$ of all ectopic ACTH secreting tumors is given by small cell lung carcinoma, the remaining are represented by other tumors, such as pancreatic, bronchial, thymic tumors and thyroid medullary carcinoma or pheochromocytoma. In a $8-19 \%$ of cases the primary tumor remains undetected (9-11). We report a fatal case of an acute Cushing's syndrome associated with immunodeficiency in a patient with an advanced pancreatic tumor metastatic to the liver at the onset of the syndrome.

\section{Case report}

A 48-year old woman was admitted to the hospital in August 2011 presenting with severe asthenia, abdominal bloating and weight gain for over a month. Her recent clinical history included a poorly-responsive blood hyperthension and endoscopically proven gastric ulcer treated with standard doses of proton pump inhibitors (omeprazole $20 \mathrm{mg} / \mathrm{die}$ ). Blood analysis showed severe anemia ( $\mathrm{Hb} 9.8 \mathrm{~g} / \mathrm{dl}$ ), reduced hematocrit (Ht 31.9\%), neutrophilic leukocytosis with marked lymphocytopenia (10.66 x103/ul; lymphocytes: $0.52 \times 10^{3} / \mathrm{ul}$ ), hypertransaminasemia (AST 56U/L; ALT 89U/l). At the time of that admission, the patient did not show any clinical features of Cushing's syndrome. Furthermore, because of the clinical picture, the patient underwent a thorough endoscopic examination, with esophagogastroduodenoscopy and colonoscopy which ruled out a gastrointestinal bleeding. The abdominal ultrasound examination showed a mass located in the head of the pancreas along with multiple liver metastases, a finding confirmed by the CT-scan. The lung was apparently spared of any metastatic lesion. A liver biopsy showed a high grade, poorly differentiated neuroendocrine carcinoma (grade G3, Ki67 of $55.9 \%$ ) At histopathology, tumor cells showed a diffuse cytoplasmic positivity for a number of neuroendocrine markers, including neuron specific enolase (NSE), synaptophysin, chromogranin A (CgA) and cytocheratin-7 and -9 (Figg. 1, 2).

Serum NSE and CgA were elevated ( $235 \mathrm{ng} / \mathrm{ml}$, n.v. $<12.5 \mathrm{ng} / \mathrm{ml}$ and $354 \mathrm{ng} / \mathrm{ml}$, n.v. $<35 \mathrm{ng} / \mathrm{ml}$, respectively).

The octreoscan scintigraphy revealed a mild accumulation in the head of the pancreas in a location compatible to that identified by CT-scan and ultrasonography. Furthermore, octreoscan evaluation indicated a radionuclide accumulation in only two lesions of the liver. These findings clearly indicated a neuroendocrine origin of the pancreatic tumor and related metastases. Three months later the patient was again hospitalized for acute sepsis due to Lysteria Monocytogenes meningitis and Staphylococcus Aureus metycillino-resistant multiple broncho pneumonitis. In addition, the patient showed a severe leukopenia, marked glucose intolerance and severe hypokalemia unresponsive to replacement treatment. Shortly after, the patient developed jaundice, rounded plethoric face, buffalo hump, hyperpigmented abdominal cutaneous striae, hirsutism and muscle weakness: all signs clearly indicative of Cushing's syndrome. Serum tests resulted as follows: ACTH 338 pg/ml (n.v.: 


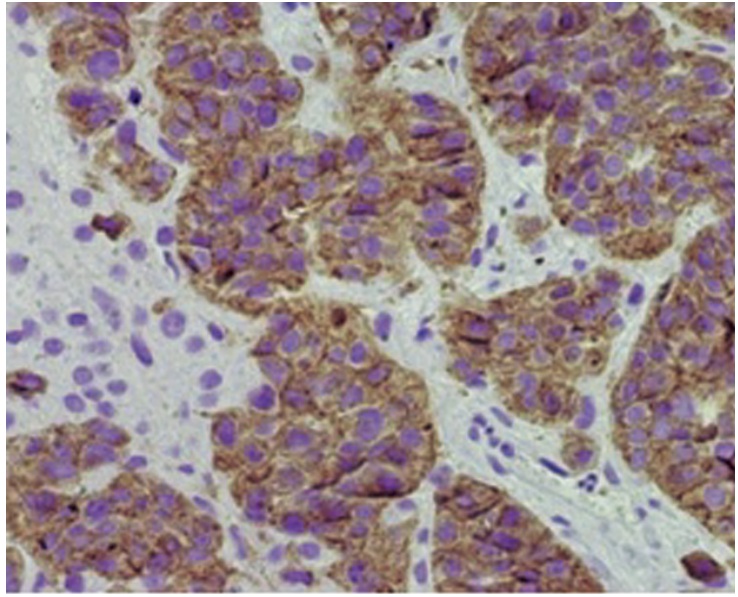

Fig. 1. Synaptophysin Hematoxylin eosin.

5-60 pg/ml); cortisol > $630 \mathrm{ng} / \mathrm{ml}$ (n.v.: 62-194 ng/ml), and free urinary cortisol $>630 \mathrm{mg} /$ die (n.v.: $36-137 \mathrm{mg} /$ die). A further immunohistochemical evaluation of the liver metastases confirmed the presence of ACTH containing cells (Fig. 2 ). Thus, taken together the clinical outcome, endocrinological laboratory assays and newly performed immunohistochemical analysis of available tissue were all consistent with an ectopic ACTH secretion by a neuroendocrine pancreatic tumor. The outcome of the disease was characterized by a rapid evolution leading the patient to death for acute septicemia unresponsive to any antibiotic treatment.

\section{Discussion}

Pancreatic neuroendocrine tumors (PNETs) are rare neoplasms, accounting for less than $3 \%$ of all pancreatic tumors and $5-7 \%$ of all neuroendocrine tumors (NETs) (12). Functioning tumors represent only $10 \%$ of PNETs (13) and they may produce peptide hormones, such as insulin, glucagon, somatostatin and pancreatic polypeptide. PNETs are generally malignant except insulinoma $(13,14)$. In this context, an even rare neoplasm is represented by pancreatic ACTH secreting tumor accounting for 1.2\% of all PNETs and 15\% of ectopic ACTH syndrome. ACTH-secreting tumors occur most frequently in adults, mainly females as the case herein illustrated. Most tumors appear to have a well-differentiated histopathological phenotype, while rare cases show a poorly-differentiated neuroendocrine profile (15-17). In this case report, we provided evidence of a female patient with a particularly aggressive form of poorly-differentiated pancreatic ACTH producing tumor. In the few cases so far published, this type of rare PNET usually presents with an aggressive behavior often characterized by metastasis at the time of diagnosis. In addition to liver, common sites of secondary location of the primitive tumor include lymph nodes, kidneys, bone, thyroid and peritoneum. Previously, a case with ovarian metastasis has been described (18). Due to the rapid progression of disease, the prognosis is poor and the survival rates were $40 \%$ and $16 \%$ at 2 and 5 years, respectively (19). The course of the tumor-related Cushing's syndrome can be either acute (usually rapidly progressive) or chronic. The acute presentation, as apparently occurred in our patient, is associated with a rapid onset of hypertension, edema, hypokalemia, diabetes, but without the typical Cushing features. This clinical phenotype is generally due to an underlying small cell lung carcinoma (20-23). In contrast, the chronic presentation of an ectopic ACTH secreting tumor is as-
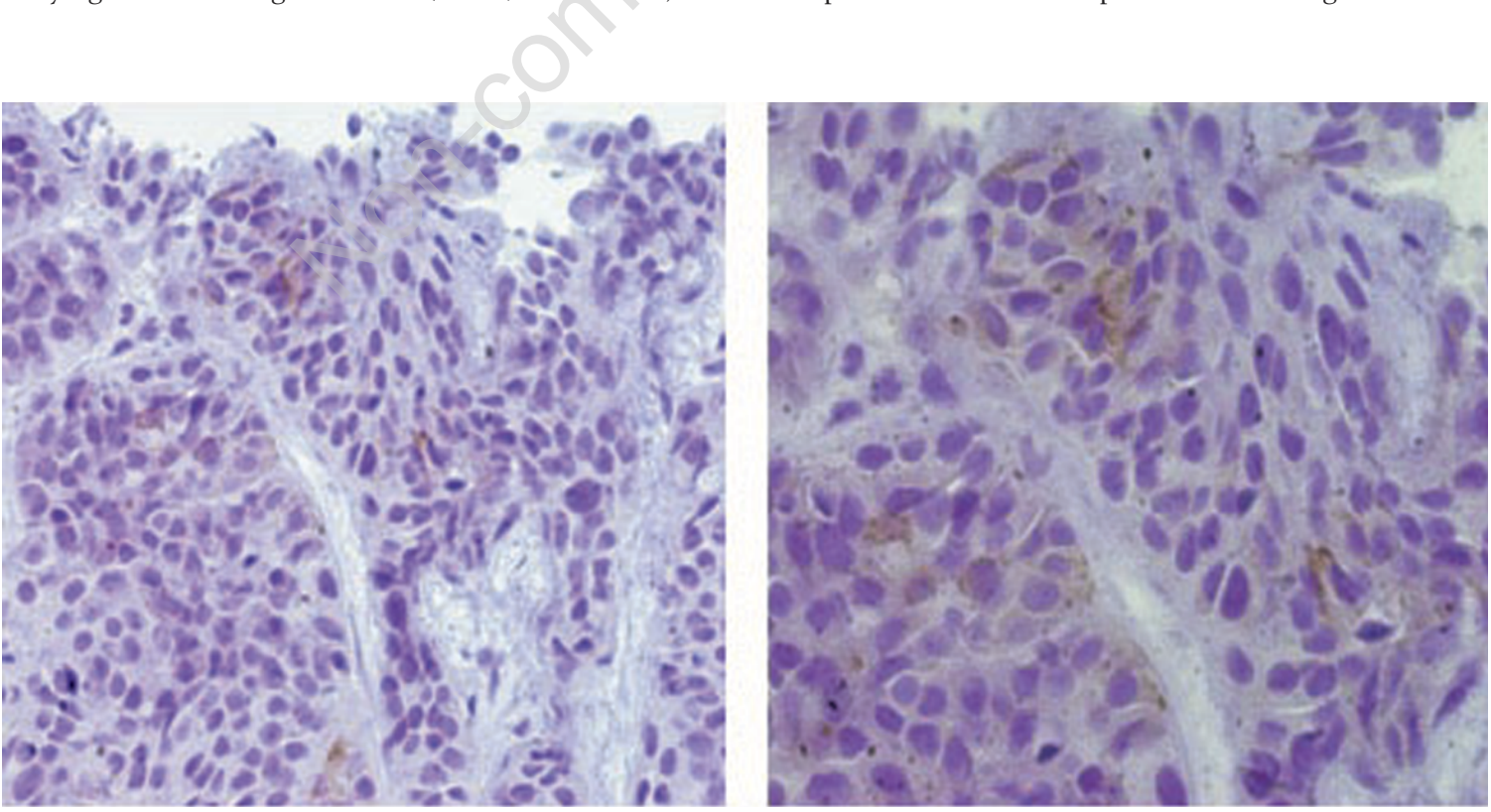

Fig. 2. Liver biopsy: Synaptophysin and Hematoxylineosin - immunostaining. 
sociated with the typical Cushing's syndrome. The case herein reported is atypical as the patient showed clinical signs indicative of both acute and chronic presentation of the tumor. Indeed, our patient had clinical manifestations suggestive of a chronic presentation (i.e., Cushing's Syndrome) rapidly complicated with a cohort of other symptoms and signs related to hypercortisolemia, including severe immunodeficiency. These features along with a number of tests led to establish a diagnosis of an ectopic ACTH secreting tumor. However, one cannot rule out the possibility that our patient had a sub-clinical Cushing syndrome preceding the overt manifestations leading to referral in our Neuroendocrine Tumor Unit.

A peculiar feature of ectopic ACTH secreting tumors, in particular those with features of a pancreatic mass, is the phenotypic behavior characterized by tumor cells changing from a non-secreting to an ACTH secreting functional profile. This changing (non-secreting to secreting) profile may be related to a loss of cell differentiation by the tumor over time (14). In our case, whether an ectopic ACTH production was due to the original pancreatic lesion or the liver metastases remained unsettled. The short time from the identification of liver metastases and Cushing's syndrome made us unable to establish a certain origin of ACTH production. The malignant potential of the tumor, as observed in this case, is further supported by the evidence that most of the metastatic lesions turned to be negative at the somatostatin receptor scintigraphy, suggesting their loss of cell differentiation.

In our patient we were able to obtain tissue only from liver biopsy which proved a positive ACTH-containing cells conceivably related to the original pancreatic tumor. As previously reported, the ACTH immunoreactive component is mixed with a subpopulation of non-secreting cells, which is a common finding in this type of PNETs (24).

A further feature of this case was the severe cortisol-dependent immunosuppression, which was a critical factor leading to the rapidly patient death. To our knowledge, this is feasible and clearly supported by the cortisol effect on the immune system, however the severity and rapid progression due to the occurrence of a septicemia is quite uncommon.

In our patient, we could not attempt any surgical or medical treatment. Wherever possible the gold standard treatment include surgical resection of the primary ectopic ACTH-secreting tumor or, as an alternative, bilateral adrenalectomy may be indicated in order to control cortisol secretion. The medical therapy is based on drugs inhibiting the synthesis and secretion of cortisol, such as ketoconazole, metyrapone and mitotane (25-26). Usually, ketoconazole and metyrapone are effective, although often limited by the lack of control of hypercortisolism related to unsuppressed ACTH secretion (27). In this line, our patient had such a rapid evolution of the clinical picture hampering any possible treatment with somatostatin analogues or other novel cytostatic agents, e.g. everolimus now indicated in patients with advanced PNETs (28).

In conclusion, this case reported appears of special interest for internists and specialists alike as it showed a rapid progression of an atypical Cushing's syndrome related to an ACTH secreting PNET. The present clinical report highlights the aggressive nature of this tumor and alerts on the rapidly fatal course of this condition.

\section{References}

1. Hodish I, Giordano TJ, Starkman MN, Schteingart DE. Location of ectopic adrenocortical hormone-secreting tumors causing Cushing's syndrome in the paranasal sinuses. Head Neck. 2009; 31: 699-706.

2. Mintzer DM, Zheng S, Nagamine M, Newman J, Benito M. Esthesioneuroblastoma (Olfactory Neuroblastoma) with Ectopic ACTH Syndrome: a multidisciplinary case presentation from the Joan Karnell cancer center of Pennsylvania Hospital. Oncologist. 2010; 15: 51-8.

3. Tritos NA, Biller BM, Swearingen B. Management of Cushing disease. Nat Rev Endocrinol. 2011; 7: 279-89.

4. Porterfield JR, Thompson GB, Young WF, et al. Surgery for Cushing's syndrome: an historical review and recent tenyear experience. World J Surg. 2008; 32: 659-77.

5. Findling JW, Raff H. Cushing's Syndrome: important issues in diagnosis and management. J Clin Endocrinol Metab. 2006; 91: 3746-53.

8. Mancini T, Porcelli T, Giustina A. Treatment of Cushing disease: overview and recent findings. Ther Clin Risk Manag. 2010; 6: 505-16.

7. Kanno K, Morokuma Y, Tateno T, et al. Olfactory neuroblastoma causing ectopic ACTH syndrome. Endocr J. 2005; 52: 675-81.

8. Koo BK, An JH, Jeon KH, et al. Two cases of ectopic adrenocorticotropic hormone syndrome with olfactory neuroblastoma and literature review. Endocr J. 2008; 55: 469-75. 


\section{casi clinici}

9. Ilias I, Torpy DJ, Pacak K, et al. Cushing's syndrome due to ectopic corticotropin secretion: twenty years' experience at the National Institutes of Health. J Clin Endocrinol Metab 2005; 90: 4955-62.

10. Isidori AM, Kaltsas GA, Pozza C, et al. The ectopic adrenocorticotrophin syndrome: clinical features, diagnosis, management and long-term follow-up. J Clin Endocrinol Metab 2006; 91: 371-7.

11. Salgado LR, Fragoso MC, Knoepfelmacher M, et al. Ectopic ACTH syndrome: our experience with 25 cases. Eur J Endocrinol 2006; 155: 725-33.

12. Yao JC, Hassan M, Phan A, et al. One hundred years after "carcinoid": epidemiology of and prognostic factors for neuroendocrine tumors in 35,825 cases in the United States. J Clin Oncol 2008; 26: 3063-72.

13. Halfdanarson TR, Rabe KG, Rubin J, et al. Pancreatic neuroendocrine tumors (PNETs): incidence, prognosis and recent trend toward improved survival. Ann Oncol 2008; 19: 1727-33.

14. Kondo T, Matsuyama R, Ashihara H, Matsuo Y, Sasaki K, Goto R, Ono K, Takaki Y, Honda Y, Iyama K, Kawashima J, Motoshima H, Tsuruzoe K, Miyamura N, Araki E. A case of ectopic adrenocorticotropic hormone-producing pancreatic neuroendocrine tumor with multiple liver metastases. Endocr J. 2010; 57: 229-36.

15. Corrin B, Gilby ED, Jones NF, Patrik J. Oat cell carcinoma of the pancreas with ectopic ACTH secretion. Cancer 1973; 31: 1523-7.

16. Kitchens CS, Alexander RW. Cushing's syndrome secondary to a neuroendocrine tumor: relapse after bilateral adrenalectomy. Cancer 1981; 48:1873-6.

17. Miehle K, Tannapfel A, Lamesch P, Borte G, Schnker E, Kluge K, et al. Pancreatic neuroendocrine tumor with ectopic adrenocorticotropin production upon second recurrence. J Clin Endocrinol Metab 2004; 89: 3731-6.

18. Öberg KC, Wells K, Seraj IM, et al. ACTH-secreting islet cell tumor of the pancreas presenting as bilateral ovarian tumors and Cushing's syndrome. Int J Gynecol Pathol 2002; 21: 276-80.

19. Clark ES, Carney JA. Pancreatic islet cell tumor associated with Cushing's syndrome. Am J Surg Pathol 1984; 8: $917-24$.

20. Maton PN, Gardner JD, Jensen RT. Cushing's syndrome in patients with the Zollinger-Ellison syndrome. N Engl J Med 1986; 315: 1-5.

21. Krakoff J, Koch CA, Calis KA, et al. Use of a parenteral propylene glycol-containing etomidate preparation for the longterm management of ectopic Cushing's syndrome. J Clin Endocrinol Metab 2001; 86: 4104-8.

22. Newell-Price J, Trainer P, Besser M, et al. The diagnosis and differential diagnosis of Cushing's syndrome and pseudoCushing's states. Endocr Rev 1998; 19: 647-72.

23. Orth DN. Cushing's syndrome. N Engl J Med 1995; 332: 791-803.

24. Gullo L, De Giorgio R, D'Errico A, Grigioni W, Parenti M, Corinaldesi R. Pancreatic exocrine carcinoma producing adrenocorticotropic hormone. Pancreas. 1992; 7: 172-6. Review.

25. Nieman LK. Cushing's syndrome. Philadephia: WB Saunders, 2001

26. Bertagna X, Raux-Demay MC, Giulhaume B, et al. Cushing's disease. Malden: Blackwell, 2002.

27. Newell-Price J, Bertagna X, Grossman AB, et al. Cushing's syndrome. Lancet 2006; 367: 1605-17.

28. Wiedenmann B, Pavel M, Kos-Kudla B. From targets to treatments: a review of molecular targets in pancreatic neuroendocrine tumors. Neuroendocrinology. 2011; 94: 177-90. Epub 2011 Aug 31. Review. 